\title{
Der IWF im Wandel - Rückkehr zu einem neuen System
}

Der Umgang des Internationalen Währungsfonds mit zukünftigen Finanz- und Währungskrisen

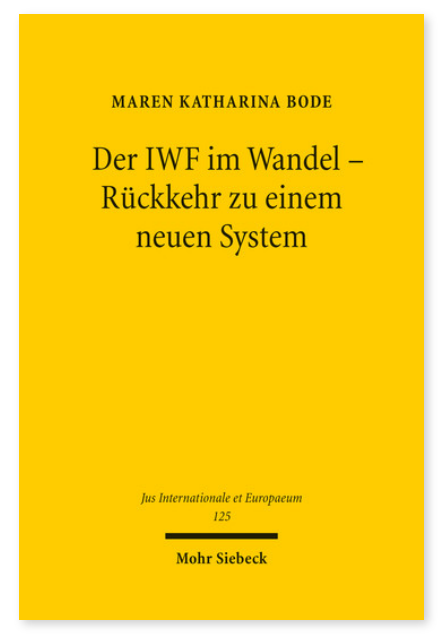

2017. XXXVI, 427 Seiten. JusIntEu 125

ISBN 978-3-16-155212-0

DOI 10.1628/978-3-16-155212-0

eBook PDF 94,00€

ISBN 978-3-16-155110-9

fadengeheftete Broschur 94,00€
Maren Katharina Bode untersucht das Handeln des Internationalen Währungsfonds im Lichte vergangener, aktueller und zukünftiger Finanz- und Währungskrisen aus rechtlicher und wirtschaftlicher Sicht. Die Besonderheit liegt in einer weitreichenden Aufarbeitung seines Verhaltens bei der Krisenbewältigung und einer strukturierten Einordnung dieses Verhaltens in verschiedene Rollen. Dabei werden nicht nur seine Handlungsweisen, sondern auch die ihm hierzu entgegengebrachte Kritik systematisch analysiert und bewertet. Im Anschluss werden Lösungswege struktureller und inhaltlicher Art aufgezeigt, wie sich der IWF zukünftig ausrichten sollte. Um auf künftige Krisen angemessen und aufgabengerecht reagieren zu können, empfiehlt die Autorin die 'Rückkehr zu einem neuen System'.

Maren Katharina Bode Studium der Rechtswissenschaften an der Heinrich-Heine-Universität Düsseldorf; Aufenthalte in den USA (Boston) und Sri Lanka (Colombo); 2016 Promotion; derzeit Rechtsreferendarin.

Jetzt bestellen:

https://mohrsiebeck.com/buch/der-iwf-im-wandel-rueckkehr-zu-einem-neuen-system-9783161552120?no_cache=1 order@mohrsiebeck.com

Telefon: +49 (0)7071-923-17

Telefax: +49(0)7071-51104 